\title{
Chronic myeloid leukemia in a pediatric population in the Congo
}

\author{
Lydie Ocini Ngolet ${ }^{1}$, Jenny Guelongo Okouango Ova ${ }^{1}$, Alexis Elira Dokekias ${ }^{1}$
}

\begin{abstract}
Objective: Chronic myeloid leukemia is a rare hematological malignant disorder among children and adolescents for which data are scare in Africa. The aim of the study is to report clinical, biological feature of children with chronic myeloid leukemia. Additionally, describing cytogenetic response to imatinib and adherence of children to the drug.

Patients and Methods: A retrospective study was carried out from January 2007 to December 2016 (10 years) in the department of Hematology at the Teaching Hospital in Brazzaville. Four of 52 patients admitted during the period for chronic myeloid leukemia, were children. We collected data from these children's medical records for analysis.
\end{abstract}

Results: They were four adolescents ( 2 boys and 2 girls) with a median age of 13.75 years at the time of diagnosis (range 11.2 and 16 years) that presented at the chronic phase of the the chronic myeloid leukemia. Delay diagnosis was 4 months. All adolescents presented with a voluminous splenomegaly (median size: 16.75 $\mathrm{cm}$ ) and high white blood cells count: $133.37 \mathrm{G} / \mathrm{L}$ (range: 60.7 and $219 \mathrm{G} / \mathrm{L}$ ). The response to imatinib was poor. None patient was adherent to the treatment.

Conclusion: Chronic myeloid leukemia in children in the Congo is rare. Abdominal pain and voluminous splenomegaly are the main finding symptoms of the malignancy. Despite the delayed diagnosis of the disease, children present at chronic phase. The response to imatinib is poor as children are not adherent to the treatment.

Keywords: Chronic myeloid leukemia, children, Congo

\section{Introduction}

Chronic myeloid leukemia (CML) is a positive Philadelphia chromosome clonal myeloproliferative disorder that affects mostly in adulthood. It is rare among children and accounts for 2-3\% of all childhood leukemia (1). Even though CML pediatric and adult population share the same fusion gene BCR$\mathrm{ABL}$, Krumbholz, et al have shown that breakpoint distribution in BCR in children is different than adult (2). Besides pediatric CML compared to adult one is described as more aggressive (3). Imatinib is, as in adults, an effective first line treatment in children and adolescents with CML (1). It has showed impressive complete cytogenetic response rates (1). In our knowledge only one study has described specifically the CML pattern in pediatrics population in Sub Saharan Africa (4). We are complementing it by describing the clinical, biological pattern of CML in children as well their response and adherence to imatinib.

\section{Patients and Methods}

The retrospective study took in the Hematology department at the teaching hospital, largest hospital in the country from January 2007 to December 2016 (10 years). All medical records of patients younger than 18 years at the enrollment who had chronic myeloid leukemia were enrolled in the study. For each patient, we collected demographic, clinical and biological data. The hematological and cytogenetic responses to imatinib were analyzed with regard to the European Leukemia Net Guidelines and U.S National Comprehensive Cancer Network (NCCN) Guidelines (5).

Adherence to imatinib was assessed by counting the number of days of imatinib taken. Patients were defined as non adherent when there were discontinuing their treatment for at least ninety days.

Received 21-03-2017 Accepted 28-03-2017 Available Online 31-03-2017

1Marien Ngouabi University, Clinical Hematology Unit, Brazzaville Teaching Hospital, Brazzaville, Congo

* Corresponding Author: Lydie Ocini Ngolet E-mail: lngolet@yahoo.fr Phone: + 242055119860 
Statistical analysis: For the description of each quantitative variable, median, range, frequencies and percentages were calculated.

\section{Results}

Clinical and biological characteristics are shown in the table 1. Four children $(7.69 \%)$ on 55 patients with chronic myeloid leukemia were included in the study. They were two males and two girls with an average age of 13.75 years (range 11.6 and 16.3 years). The delay diagnosis was 4 months (range 1 and 6 months). Abdominal pain was the most common symptoms. All patients presented a splenomegaly with a median size of $16.75 \mathrm{~cm}$ (range 14 and $19 \mathrm{~cm}$ ).

Initial cell blood counts accounted for an average leukocytosis at $133.37 \mathrm{G} / \mathrm{L}$ (range 60.7 and $219 \mathrm{G} / \mathrm{L}$ ). At the differential, blast accounted in average for $2.3 \%$ (range 1 and $5 \%$ ).
The average hemoglobin rate was $7.45 \mathrm{~g} / \mathrm{dL}$ (range 7.9 and $11.3 \mathrm{~g} / \mathrm{dL}$ ) and platelets $435.25 \mathrm{G} / \mathrm{L}$ (range $359-480 \mathrm{G} / \mathrm{L})$.

\section{All patients presented at the chronic phase.}

Imatinib was initiated at $400 \mathrm{mg}$ daily for all patients. The median time to achieve a complete hematological response was 8 weeks ( 4 and 9.5 weeks). All patients were not adherent to imatinib. They discontinued their treatment on themselves without the agreement of their medical providers. The average duration of the discontinuation was 98 non cumulative days (range 90 and 128 days).

At 6 months three patients $(75 \%)$ showed minor cytogenetic responses and one $(25 \%)$ did not respond to the treatment.

Table 1: Clinical and biological characteristics of CML children (+ : present, - : absent)

\begin{tabular}{lcccc}
\hline Gender & $\begin{array}{c}\text { Patient } \mathrm{N}^{\circ} 1 \\
\mathrm{M}\end{array}$ & $\begin{array}{c}\text { Patient } \mathrm{N}^{\circ} 2 \\
\mathrm{~F}\end{array}$ & $\begin{array}{c}\text { Patient } \mathrm{N}^{\circ} 3 \\
\mathrm{M}\end{array}$ & $\begin{array}{c}\text { Patient } \mathrm{N}^{\circ} 4 \\
\mathrm{~F}\end{array}$ \\
\hline Age in year & 11.6 & 13.2 & 14 ans & 16.3 \\
Delay delay diagnosis in month & 1 & 5 & 4 mois & 6 \\
& & & & \\
Symptoms & - & - & - & - \\
Fever & + & + & + & - \\
Fatigue & - & + & + & + \\
Lost of weight & + & + & + & + \\
Abdominal pain & 14 & 19 & 15 & 19 \\
Splenomegaly size in cm & & & & \\
& & & & \\
Blood count (G/L) & 83,8 & 219 & 60,7 & 170 \\
GB & 11,3 & 7,9 & 8.3 & 10.8 \\
Hb & 429 & 480 & 359 & 473 \\
Plaquettes & 1 & 5 & 1 & 2.3 \\
Blast (\%) & Chronic & Chronic & Chronic & chronic \\
Phase of CML & \multicolumn{5}{c}{} \\
\hline
\end{tabular}




\section{Discussion}

Pattern of CML in the African continent have been broadly reported, however most of them were focused on the adult population. CML in children remain unexplored (4). Few reports in the region have been published. To our knowledge, no one of them debates the topic of adherence to the treatment $(4,6)$. CML is also in the African continent a rare blood disorder in the childhood. In the Hematology department in Brazzaville, which is the unique department that manages hematological malignancies in the country, it constitutes $7.69 \%$ on a cohort of 52 patients. In Senegal CML in children accounts for $11 \%$ in and $1.2 \%$ in eastern India $(4,7)$.

It appears that preteens and teenagers are more affected by CML in the pediatric population with an average age that ranges from 11.5 to 16 years $(4,6,7)$ Children from low and middles resources countries are older at the time of the diagnosis due to the long delay diagnosis of the CML $(8,9)$. Consequent to the tardy diagnosis, children present with abdominal pain and voluminous splenomegaly that can confuse physicians to tropical splenomegaly in our region. They also have elevated white blood cell (WBC) counts. Fall et al showed an average count of $244 \mathrm{G} / \mathrm{L}$ of WBC and a moderate anemia (4). Thrombocytosis is rare in children (3). Despite delayed diagnosis of the CML, children as well as adults in our cohort present at the hospital at chronic phase of the disease (8).

Cytogenetic responses monitored at 6 months of treatment showed poor performance of imatinib in our series since none complete cytogenetic responses (CCR) were noticed. El-Affy, Fall and Rault et al reported respectively 53,55 and $75 \%$ of complete cytogenetic responses $(4,6,7)$. Nonetheless, we should be cautious while comparing these rates. Indeed when we peruse the results of Rault et al, we can read that at 6 months of the treatment, the CCR was monitored only on 4 patients over 9 and sole one patient $(25 \%)$ showed a CCR (7). Opimal response to imatinib is lower in the pediatric when we compare with adults (4). Poor adherence of children mainly adolescent is usually reported as cause of this low performance (10).

\section{Conclusion}

Chronic myeloid leukemia in children is a rare in the Congo. It shares clinical and biological feature with adults. However, the lower performance of the imatinib in this population related in some part to the poor adherence of the treatment, request specific interventions and management by the medical team.
Conflict of Interest: The authors declare no potential conflicts of interest with respect to the research, authorship, and/or publication of this article.

Acknowledgement: Author Contributions: NLO; Planing of Research and examination of patients. Preperation of draft, GOOJ; Revision of manuscript, EDA; Approval of the final version of the manuscript. All authors read and approved the final manuscript

Ethical issues: All Authors declare that Originality of research/article etc... and ethical approval of research, and responsibilities of research against local ethics commission are under the Authors responsibilities. The study was conducted due to defined rules by the Local Ethics Commission guidelines and audits.

\section{References}

1. Millot F, Baruchel A, Guilhot J, et al. Imatinib is effective in children previously untreated chronic myelogenous leukemia in early chronic phase. Results of the French national Phase IV trial. J Clin Oncol.2011; 29: 2827-32.

2. Krumbholz M, KarlvM, Tauer JT, et al. Genomic BCRABL1 breakpoints in pediatric chronic myeloid leukemia genes chromosomes. Cancer 2012; 51(11): 1045-53.

3. Hijiya N, Schultz KR, Metzler M, Millot F, et al. Pediatric chronic myeloid leukemia is a unique disease that requires a different approach. Blood. 2016; 127(4): 392-9.

4. Fall S, Ndiaye FSD, Dior OD, Sall AF, et al. Leucémie myeloide chronique des sujets jeunes: expérience dans une unité d'hématologie Clinique au Sénégal. Revue d'oncologie hématologie pédiatrique. 2015; $3: 170-4$.

5. S. O' Brien, E Berman, H Borghuei, et al. NCCN clinical practice guidelines in oncology. I Natl Compr Cancer Netw. 2009; 7: 987-1020

6. El-Affy M, Alaa M, Haddad AL and Ahmed DH. Managelent of chronic myelogenous leukemia in the pediatric age group: imatinib mesylate or SCT. Journal of the Egyptian Nat. Cancer Inst. 2010; 22(4): 227-32.

7. Raut L, Bohara VV, Ray SS, Charkrabati P and Chaudhuri V. Chronic myeloid leukemia in children and adolescent: A single center experience from Eastern India. South Asian J. Cancer. 2013; 2(4): 260-4.

8. Ngolet LO, Kocko I, Galiba Atipo Tsiba O, et al. Imatinib mesylate in chronic myelogenous leukemia : a Congolese experience. EAMJ. 2016; 93(9): 118- 122.

9. Diallo DA,Cissoko LS,Cissoko Y, Diallo Y, Baby M et al. Epidémiologie actuelle des hémopathies malignes dans les services d'hématologie oncologie médicale et de médecine interne de l'hôpital du Point G, Bamako, Mali. Mali Médical. 2005; 20 (4):1-8.

10. S. Noens, M.R Van Liende, R De Bock et al. Prevalence, determinants, and outcomes of non adherence to imatinib therapy in patient with chronic myeloid leukemia: the ADAGIO study. Blood. 2009; 22 (113): 5401-11. 